\title{
PRÁTICAS DOS PROFESSORES ALFABETIZADORES DA EJA: $O$ QUE FAZEM OS PROFESSORES, 0 QUE PENSAM OS SEUS ALUNOS?'
}

\author{
Andréa Tereza Brito Ferreira* \\ Eliana Borges C. de Albuquerque** \\ Artur Gomes de Morais*** \\ Josemar Guedes Ferreira****
}

RESUMO: Esta pesquisa buscou analisar práticas de alfabetização de professoras da Educação de Adultos e a relação dessas com a aprendizagem dos alunos no que se refere à apropriação da escrita alfabética. A pesquisa foi desenvolvida em duas turmas do módulo I de Recife. Foram realizadas observações de aulas e entrevistas com professoras e um grupo de alunos para perceber as expectativas sobre o aprendizado da leitura e da escrita. A análise revelou que as professoras desenvolviam práticas que priorizavam a expressão oral, cópias, leitura de textos pela docente e interpretação coletiva dos mesmos, ao lado de poucas atividades de reflexão sobre o sistema de escrita alfabética. As expectativas que os alunos tinham ao retornar à escola não foram confirmadas. A maioria não progrediu significativamente na aprendizagem da leitura e escrita e muitos se culpavam pelo "fracasso".

Palavras-chave: Alfabetização; EJA; Prática Docente.

\footnotetext{
* Doutora em Sociologia pela Universidade Federal de Pernambuco (UFPE); Professora do Programa de Pós-graduação em Educação da Universidade Federal de Pernambuco (UFPE); Membro do Centro de Estudos em Educação e Linguagem (UFPE). E-mail: atbrito@superig.com.br

* * Doutora em Educação pela Universidade Federal de Pernambuco (UFPE); Professora da Universidade Federal de Pernambuco (UFPE). E-mail: elianaba@terra.com.br

*** Doutor em Psicologia pela Universidade Federal de Pernambuco (UFPE); Professor da Universidade Federal de Pernambuco (UFPE). E-mail: agmorais@terra.com.br

**** Mestrando em Educação pela Universidade Federal de Pernambuco (UFPE). E-mail: josemarferreira@hotmail.br
} 


\section{TEACHING PRACTICES OF EJA LITERACY TEACHERS: WHAT DO TEACHERS DO, WHAT DO THEIR STUDENTS THINK?}

ABSTRACT: The purpose of this research was to analyze the literacy teaching practices of teachers of Youth and Adult Education and the relationship between such practices and the actual learning of their students, regarding the acquisition of the alphabetic writing system. The research involved two groups of module I in a literacy class given at two public schools of Recife, Pernambuco. Classes were observed and interviews with the teachers and with a group of students were carried out, in order to grasp their expectations regarding their learning of reading and writing. Analysis showed that the teachers developed a literacy teaching practice, which gave priority to oral expression, the construction and copy of sentences, text readings by the teacher and text interpretation by the students, as well asa few reflective activities about the alphabetic writing system. It was clear that the expectations of the students when returning to school, that is, to learn to read and write, were not fulfilled. The large majority did not advance much, and most of them blamed themselves for their alleged "failure".

Keywords: Literacy; Youth and Adult Education; Teaching Practices.

\section{Introdução}

A Educação de Jovens e Adultos (EJA) se inscreve no cenário educacional brasileiro com questões muito específicas. Essas questões se relacionam tanto com a constituição da identidade dos sujeitos - geração, raça, gênero e classe social - como com as práticas docentes, principalmente com aquelas destinadas ao ensino da leitura e da escrita. A preocupação com a alfabetização de adultos surgiu muito tardiamente, no país, e, ainda hoje, percebem-se as marcas de um longo e difícil processo na busca de propostas permanentes de escolarização voltadas para esse segmento.

Atualmente, os alunos da EJA ainda são alvo de materiais didáticos e de práticas inadequadas às suas especificidades. As práticas de ensino da EJA, muitas vezes, estão baseadas nas habilidades de "codificação" e "decodificação", que destacam a memorização de sílabas e/ou palavras e/ou frases soltas, sem a devida atenção a uma construção mais reflexiva do Sistema de Escrita Alfabética (SEA) e de um trabalho que valorize as distintas fontes e gêneros textuais que a sociedade faz circular. Outro aspecto a salientar dessa forma de conceber o ensino da EJA é a infantilização dos materiais e práticas, que deixam os alunos distantes das suas realidades, seja pela questão geracional, seja pelos aspectos específicos de uma camada social desfavorecida. Este artigo põe em discussão algumas 
práticas de professores de alfabetização de Jovens e Adultos, tomando como princípio as diferentes maneiras de fabricação do cotidiano escolar, considerando, também, o que os alunos desse segmento de ensino pensam sobre as práticas docentes.

\section{Práticas de alfabetização de adultos: algumas reflexões}

A história da alfabetização, no Brasil, integra-se a um processo de reconstrução de diversas histórias, mas um aspecto a se destacar, nos diferentes tempos históricos, são as práticas de ensino da leitura e da escrita que envolvem tanto crianças como pessoas jovens e adultas.

Até há bem pouco tempo, a escrita era considerada um código, e, para aprendê-la, defendia-se que bastava dominar as técnicas de codificação e decodificação. A leitura e a escrita praticadas na escola eram padronizadas, dando ênfase à memorização de letras, sílabas e palavras sem significado. Pedagogicamente, a alfabetização considerada como o ensino das habilidades de codificação e decodificação foi transposta para a sala de aula, no final do século XIX, por meio da criação de diferentes métodos de alfabetização - métodos sintéticos e métodos analíticos, método misto versus método natural - que buscavam padronizar a aprendizagem da leitura e da escrita (CHARTIER, 2011). As cartilhas relacionadas a esses métodos passaram a ser amplamente utilizadas como importante material de ensino nessa área.

No contexto brasileiro, a mesma sucessão de oposições pode ser constatada, como observado por Mortatti (2000). Os "métodos sintéticos" tomavam como ponto de partida a letra (método alfabético ou da soletração), o fonema (método fônico), ou a sílaba (método silábico ou da silabação), que eram combinados, por meio de um processo de síntese, em unidades linguísticas maiores (palavras, frases e textos). Já os "métodos analíticos" (ou globais), ao contrário dos sintéticos, partiam de unidades maiores da língua: palavra (método da palavração), frase (método da sentenciação) e texto (método global). Nesses últimos métodos, as palavras, as frases ou os textos eram decompostos, por meio de um processo de análise, em unidades linguísticas menores (sílabas, letras e palavras): o texto era decomposto em frases, que, por sua vez, eram decompostas em palavras e, assim, sucessivamente. 
Braslavsky (1988) faz outra distinção em relação a esses dois blocos de métodos, ao considerar que os sintéticos partem de elementos não significativos da palavra (letras, fonemas, sílabas), e os analíticos, de unidades significativas da linguagem (palavra, frase ou texto). Para essa autora, essa classificação parece mais apropriada porque "leva em conta que a leitura é um fato linguístico e que é essencialmente compreensão da linguagem escrita". De qualquer modo, não se deve esquecer que as "unidades com significado" dos métodos analíticos tendiam a não ter relação com os contextos de vida dos aprendizes e a serem muito artificiais.

Para Morais e Albuquerque (2004), os métodos tradicionais, independentemente de serem sintéticos ou analíticos, partilhavam de uma concepção empirista-associacionista de ensino e aprendizagem. Se o ponto de partida para o ensino da leitura e escrita variava (textos nos métodos globais, fonemas nos métodos fônicos, etc.), era comum a perspectiva de que, para ensinar o Sistema de Escrita Alfabética (doravante, SEA), a escola deveria transmitir ao aluno informações prontas sobre as relações som-grafia, cabendo a ele memorizá-las, "fixá-las". Nessa perspectiva, como esses métodos concebiam a escrita alfabética como um código, seu aprendizado dependeria de capacidades psicomotoras ou perceptivas e mnemônicas que, em diferentes momentos do século XX, passaram a ser concebidas como requisitos para a alfabetização.

Apesar de ter havido um amplo debate, nas duas últimas décadas, sobre o ensino e a aprendizagem da língua escrita, observa-se que muitas escolas ainda continuam praticando um ensino de alfabetização limitado ao que se encontrava nas antigas cartilhas baseadas em métodos sintéticos e analíticos de ensino da leitura e da escrita. Tal como apontaram Moura e Morais (2001), mesmo trazendo para a sala de aula textos de circulação social (notícias, letras de músicas, textos literários, etc.), muitos professores de EJA continuariam praticando um ensino do sistema de escrita baseado no tradicional "método silábico" de alfabetização e desconsiderariam que os alunos adultos, por estarem há mais tempo inseridos em experiências de leitura e escrita, possuem conhecimentos diversos sobre a escrita alfabética. Muitas vezes, cria-se uma evidente contradição: leem-se e escrevem-se textos interessantes, mas o ensino da escrita alfabética não muda. Os professores desejam que o aluno seja "sujeito" de sua aprendizagem, que ele aprenda refletindo e construindo sua compreensão, mas propõem, no dia a dia, tarefas essencialmente mecânicas, como a cópia e junção de sílabas. 
Paulo Freire, em seu trabalho de alfabetização de jovens e adultos desenvolvido no início da década de 60 , rompeu com muitos aspectos constitutivos dos métodos tradicionais de alfabetização, tais como: trabalho com palavras não significativas para os alunos; necessidade de partir de sílabas mais simples para as mais complexas; uso de textos cartilhados (construídos pelos autores do livro com o uso de palavras já trabalhadas em lições anteriores); concepção de aluno como tábula rasa, cujo conhecimento sobre a língua teria que ser transmitido pelo professor, etc. Para ele, os adultos analfabetos eram produtores de cultura e de conhecimento, e o processo de alfabetização deveria partir de suas experiências. Como se sabe e já é tão divulgado, para Freire, "a leitura de mundo precede a leitura da palavra" (1985, p.24).

No entanto, a partir de suas concepções, foi criada uma metodologia para alfabetizar que se baseava em certas características do método silábico de alfabetização (o mais usado na época). O trabalho partia de uma palavra geradora e do ensino dos padrões silábicos relacionados às sílabas constitutivas da palavra em estudo.

Considerando a importância do trabalho de Paulo Freire para o campo da Educação de Jovens e Adultos, Soares (2003) afirma que ele vai muito além do que se chamou "método de alfabetização Paulo Freire". Mas, mesmo assim, muitos professores continuam adotando o método silábico (que prioriza o trabalho com palavras geradoras e os padrões silábicos das sílabas que as compõem) para alfabetizar adultos e, com isso, desconsideram os conhecimentos que esses sujeitos possuem sobre a leitura e escrita e não organizam suas práticas de ensino de modo a fazê-los evoluir em tais conhecimentos.

Segundo Galvão e Soares (2004), na pedagogia freireana:

O saber e a cultura populares são valorizados e o analfabeto considerado produtor de conhecimentos: a educação deveria ser, assim, dialógica e não bancária. Por isso, Paulo Freire propunha que, em lugar das cartas do ABC ou das cartilhas, a própria realidade do educando estivesse no centro do processo de alfabetização. A partir do conhecimento dessa realidade, o educador selecionaria algumas palavras - denominadas geradoras - que pudessem desencadear um processo de problematização dessa mesma realidade e as formas de superá-la e, ao mesmo tempo, servissem como ponto de partida para o ensino dos padrões silábicos da língua (GALVÃO; SOARES, 2004, p.43). 
Diversas pesquisas sobre aprendizagem da leitura e da escrita foram desenvolvidas a partir dos anos 1980 e tiveram muita influência no Brasil e no mundo, principalmente as desenvolvidas no campo da psicolinguística (por Ferreiro, Teberosky, Foucambert, etc.). O que a maioria desses trabalhos apresenta em comum é o fato de revelar que as atividades pedagógicas que trabalham unicamente com as habilidades de decifração na alfabetização estão mais próximas do desenvolvimento de um fazer técnico e/ou mecânico do que do desenvolvimento da compreensão do processo da leitura e da escrita (GOIGOUX, 2004).

Rompendo com a concepção de língua escrita como código, o qual se aprenderia a partir de atividades de memorização, Ferreiro e Teberosky (1984) defenderam uma concepção de língua escrita como um sistema de notação que, no nosso caso, é alfabético. Emília Ferreiro (1983) realizou pesquisas com adultos não alfabetizados e observou diferenças e semelhanças nas concepções de escrita em adultos e crianças. Com base nesses estudos, a autora defende que o conhecimento que os adultos possuem sobre o sistema de escrita é mais amplo e específico que os das crianças. Dentro dessa perspectiva, a autora observou que, mesmo sem estar alfabetizado, o adulto tem maior compreensão dos usos e funções sociais da língua, o que pode favorecer uma maior aproximação e interação com o texto. Esse processo decorre do fato de esses sujeitos adultos estarem imersos em práticas sociais de leitura e escrita, seja no trabalho ou em eventos da vida privada, e/ou por já terem sido escolarizados em algum momento em suas trajetórias. Se isso era a realidade em 1983, imagine-se hoje, três décadas depois, quando as práticas de leitura e escrita foram tão ampliadas pela difusão de tecnologias digitais.

A experiência dos adultos com a língua escrita é bem mais ampla do que a da criança, e isso acontece devido ao próprio tempo de vivência e, mais ainda, ao contato e necessidades de utilizar a língua escrita em diversas situações, tais como: identificar produtos nas prateleiras dos supermercados, seguir instruções para fazer uma máquina funcionar, pegar um ônibus ou seguir uma receita. Nessas e em outras situações, os adultos não alfabetizados são desafiados cotidianamente a utilizar a leitura, mesmo sem dominá-la, o que faz com que eles tenham uma maior compreensão das funções sociais da escrita. Porém, diferentemente do que acontece com as crianças, esses sujeitos apresentam resistência em escrever a partir dos conhecimentos que possuem, pois têm consciência 
de que "não sabem" escrever, o que ocorre menos com a criança (SOUZA, 2012).

Como observado por Ferreiro (1983), a vivência com a língua escrita faz com que algumas características que são observadas entre as crianças na fase pré-silábica já tenham sido superadas pelo adulto. No geral, os adultos, mesmo analfabetos, sabem que, para escrever, é preciso usar letras e não números ou qualquer outro símbolo. $\mathrm{Na}$ escrita silábica, os adultos enfrentam os mesmos conflitos que as crianças: a exigência de uma quantidade mínima de letras e a não repetição de letras sequenciadas. Os adultos, assim como as crianças, chegam à fase alfabética partindo da hipótese da necessidade de usar duas letras para escrever cada sílaba, passam então a estabelecer relação entre grafemas e fonemas e, a partir daí, começam a enfrentar os problemas ortográficos da língua. Segundo Ferreiro (1983), essa jornada, pela qual crianças e adultos em processo de alfabetização passam, revela o grande esforço cognitivo necessário para superar uma hipótese de escrita e adotar outra.

Comparar o nível de compreensão da escrita entre adultos e crianças não significa, no entanto, desenvolver uma infantilização das atividades pedagógicas. É preciso levar em consideração toda a bagagem histórica que os sujeitos adultos detêm, suas vivências com a língua escrita e "conhecer o adulto do ponto de vista intelectual, para desenvolver uma atitude de respeito com o adulto" (MOURA, 2001, p.116). Ao mesmo tempo, não se pode considerar que esse sujeito, por ser adulto, deva construir suas hipóteses sobre a escrita sozinho, sem uma intervenção consequente do professor.

Nesse sentido, as propostas de aprendizagem da língua materna que envolvem a compreensão dos diversos textos que estão presentes na sociedade estreitam a relação entre a cultura escrita e a cultura escolar, tornando o processo de ensino-aprendizagem muito mais significativo para o aluno. É de notório saber que esses trabalhos trouxeram grandes contribuições para o ensino da língua materna, pois é sabido que uma prática de ensino na qual se privilegia mais a compreensão do que apenas a repetição e a memorização traz muito mais benefícios para a aprendizagem. Porém, infelizmente, essas teses acadêmicas fizeram a "vara" curvar-se para outra direção e, com isso, causaram grandes problemas aos professores, que, dentro dessa confusão teórica, minimizaram o trabalho envolvendo palavras e suas unidades menores (sílabas, letras/fonemas), funda- 
mentais para a compreensão do SEA e considerados, a partir de então, sem importância. Com essa "ditadura do texto" (MORAIS, 2012), muitos alunos - crianças e adultos - têm frequentado a escola, mas não conseguem avançar, de forma significativa, no processo de apropriação da escrita alfabética, de modo a compreender o seu funcionamento e dominar suas convenções.

Alguns trabalhos buscam vencer essa dualidade, ou melhor, tentam mostrar que o trabalho sistemático com as unidades menores da palavra pode ser associado a um trabalho de compreensão envolvendo diferentes textos (GOIGOUX, 2004; ALBUQUERQUE; MORAIS; FERREIRA, 2008; CRUZ, 2012). Com base nos estudos sobre o letramento, Magda Soares (1998) também associa a prática de alfabetização, propriamente dita, com o trabalho com os gêneros textuais. Essa autora faz uma distinção entre os termos alfabetização e letramento. $\mathrm{O}$ primeiro corresponderia à ação de ensinar/aprender a ler e a escrever, enquanto o segundo é visto como o estado ou a condição de quem não apenas sabe ler e escrever, mas cultiva e exerce as práticas sociais que usam a escrita. Segundo a referida autora, "alfabetizar e letrar são duas ações distintas, mas não inseparáveis, ao contrário: o ideal seria alfabetizar letrando, ou seja: ensinar a ler e escrever no contexto das práticas sociais da leitura e da escrita, de modo que o indivíduo se tornasse, ao mesmo tempo, alfabetizado e letrado" (SOARES, 1998, p.47). Essa preocupação com a alfabetização de forma contextualizada, envolvendo tanto os textos que estão presentes na sociedade, como um trabalho sistemático com as unidades menores que compõem as palavras, vem sendo discutida na Educação de Jovens e Adultos (MORAIS, 2004; ALBUQUERQUE; BRITO FERREIRA, 2008; LEAL, 2008).

A EJA, nos últimos anos, vem sendo pensada de modo a considerar o aluno como um ser social que tem experiências diárias com o mundo letrado, anteriores à sua entrada na escola oficial, experiências estas que possibilitam o desenvolvimento de conhecimentos que envolvem, também, a escrita alfabética. Como já dito, muitos adultos analfabetos sabem, por exemplo, que as palavras são escritas com letras (e conseguem identificar algumas delas) e possuem um repertório de palavras que conhecem de cor, o que foi observado por Gléria (2010).

Além das intervenções necessárias dos professores em relação à especificidade do ensino do sistema de escrita alfabética, é importante que os docentes entendam também que seus alunos (crianças ou adultos), 
como se viu, participam constantemente de eventos e práticas de leitura e escrita, o que não pode ser desconsiderado, ao pensar as práticas docentes da EJA. Estudos ${ }^{2}$ revelaram que muitos alunos que aprenderam os sinais gráficos não conseguiam fazer uso dessa ferramenta na sua vida social: não conseguiam ler e compreender textos, assim como expressar suas ideias e vontades por meio de textos escritos por eles. Diante dessa questão, as discussões sobre o letramento, tendo como principal pressuposto a ideia de que é preciso inserir o aluno nas diferentes práticas de linguagem, levam a pensar que é necessário desenvolver ações cotidianas na escola, ações que ajudem o estudante a conviver com os textos que estão presentes nas diferentes esferas sociais de interação, ao mesmo tempo em que se apropria do SEA.

Nesse sentido, torna-se evidente que existem questões específicas no processo de alfabetização dos jovens e adultos que precisam ser levadas em consideração na organização das práticas de ensino e que são, portanto, fundamentais. Porém, ao mesmo tempo, a alfabetização também não pode ser entendida de uma forma tão direta, como em uma relação de causa e efeito.

Diante dessas especificidades apontadas, hoje, quando se pensa em alfabetização na EJA, considera-se uma trajetória de estudos sobre como se ensina e como aprendem os alunos desse segmento de ensino. Essas discussões, no campo teórico, de certo modo, vêm-se materializando nas políticas e práticas de professores da EJA. Porém, como se sabe, tais mudanças não aparecem nas salas de aula da mesma forma que foram pensadas. Elas passam por transformações de diversas ordens. É sobre essa questão que o tópico a seguir se debruça.

\section{A “fabricação" das práticas docentes}

Durante muito tempo, pensou-se que o que acontece, no interior das escolas, principalmente nas salas de aula, é fruto apenas do que é estudado e planejado por pessoas especializadas nas diferentes áreas do conhecimento. Do mesmo modo, a formação de professores foi, durante muito tempo, compreendida como uma série de orientações construídas externamente e que deveriam ser seguidas ou materializadas por diferentes professores, tal qual foram estrategicamente pensadas. $\mathrm{Na}$ realidade, 
entendendo as práticas cotidianas como Michel de Certeau (1974), tais orientações não são completamente reproduzidas tal como foram estrategicamente elaboradas, elas são reconstruídas, apropriadas e "fabricadas" em diferentes realidades escolares, a partir das trajetórias de vida, política e saberes de seus atores.

$\mathrm{Na}$ prática do professor, o fazer cotidiano não resulta pura e simplesmente da aplicação direta das teorias nem das prescrições ou "novas" propostas pedagógicas. Na realidade, a prática docente é fruto das interpretações, adaptações, (re)construções, ou, como diria Certeau (1994), das "fabricações" do que é "estrategicamente" pensado para ser realizado pelos docentes.

Nessa perspectiva, levantam-se algumas questões para reflexão, neste trabalho: Quais concepções de alfabetização estão associadas às práticas de ensino da EJA na atualidade? Como o ensino da leitura e da escrita é praticado nesse segmento de ensino? Como os alunos percebem suas aprendizagens de leitura e escrita na sala de aula?

Ao se considerar que as mudanças teóricas, no ensino da língua materna, são inovações que orientam as mudanças no fazer docente, percebe-se que a incorporação do "novo", o desenvolvimento de novas práticas, de acordo com as ideias de Perrenoud (2002), dependerá, em grande medida, da transformação dos "esquemas" do sujeito, o que exigirá tempo e muito esforço por parte do professor. Por isso, o "desapego" às antigas práticas não se dá de forma imediata, instantânea nem total, como pensaram os teóricos. Existe todo um processo que envolve avanços, experimentações e recuos, que podem resultar em sucessos e fracassos nas aprendizagens dos alunos. Nesse viés, este trabalho tem como objetivo analisar as práticas de alfabetização de professores de EJA e seus reflexos nas aprendizagens dos alunos, justamente para tentar entender essas "fabricações" no cotidiano das salas de aula da Educação de Jovens e Adultos. Para isso, serão priorizadas as práticas de ensino e os conhecimentos dos aprendizes em relação ao sistema de escrita alfabética. 


\section{Percurso metodológico da pesquisa}

Neste trabalho, adota-se a abordagem da pesquisa qualitativa, em virtude dos objetivos da pesquisa e da natureza do objeto de estudo. A pesquisa de natureza qualitativa, conforme Bogdan e Biklen (apud LÜDKE; ANDRÉ, 1986, p.13), "envolve a obtenção de dados descritivos, obtidos no contato direto do pesquisador com a situação estudada, enfatiza mais o processo do que o produto e se preocupa em retratar a perspectiva dos participantes".

Para o desenvolvimento da pesquisa, adotam-se dois procedimentos metodológicos:

Observações de aulas: foram realizadas 18 observações de aulas em duas turmas de alunos da EJA regular (Módulo I), de duas escolas públicas municipais da cidade de Recife. Foram oito aulas na turma da professora Marta e 10 na da professora Rubinalva. ${ }^{3}$ A professora Marta tem formação em Magistério do $2^{\circ}$ Grau e trabalha há 17 anos na EJA, enquanto a professora Rubinalva é formada em Pedagogia e trabalha há nove anos com alunos do mesmo segmento.

Entrevistas com alunos: Foram entrevistados, no final do ano letivo, oito alunos de cada turma, os quais foram selecionados por serem os mais frequentes às aulas. O objetivo era o de conhecer as expectativas dos alunos em relação à aprendizagem da leitura e da escrita e saber se tais expectativas tinham sido contempladas e o que acharam da experiência escolar vivenciada.

$\mathrm{Na}$ análise dos dados, foi utilizada como referencial a análise de conteúdo, segundo Bardin, pois esse tipo de análise compreende "um conjunto de instrumentos metodológicos cada vez mais subtis em constante aperfeiçoamento que se aplicam a 'discursos' [...] extremamente diversificados" (BARDIN, 1977, p.9).

Será feita, a seguir, uma descrição de como estavam constituídas as turmas das duas professoras.

Turma da Professora Marta (turma 1): Nesta turma, foram matriculados alunos na faixa etária de 38 a 80 anos. As aulas eram ministradas das $19 \mathrm{~h}$ às $21 \mathrm{~h} 30 \mathrm{~min}$. A média de frequência, nessa turma, era de 15 alunos. Com base na entrevista realizada com os oito alunos (um homem e sete mulheres), percebeu-se que a maioria das alunas era composta por donas de casa, algumas delas aposentadas. Também foi possível saber que seis 
alunos tinham estudado na infância, todos com passagens curtas pela escola, e o único aluno homem entrevistado falou que tinha retornado à escola na adolescência.

Turma da Professora Rubinalva (turma 2): Nesta turma, foram matriculados cerca de 12 alunos, com idades entre 18 e 55 anos. As aulas eram ministradas no horário das $19 \mathrm{~h}$ às $21 \mathrm{~h} 30 \mathrm{~min}$. Os alunos entrevistados, na pesquisa, eram, na sua maioria, adultos do sexo masculino e trabalhavam como ajudante de pedreiro (1), serviços gerais (2), vendedor de frutas (1), jardineiro (1). As mulheres entrevistadas (3) eram donas de casa. Assim como ocorreu na turma maioria dos alunos (6) estudou na infância e/ou na adolescência, e apenas dois alunos efetivamente começaram a estudar depois de adultos.

\section{Resultados e discussões}

\section{Práticas de alfabetização da professora Marta}

A TAB. 1, abaixo, apresenta as atividades relacionadas ao ensinoaprendizagem da leitura e escrita desenvolvidas pela professora Marta nos oito dias de observação de suas aulas.

TABELA 1: Atividades desenvolvidas nas aulas da professora Marta

Recife - 2008

\begin{tabular}{|c|c|c|c|c|c|c|c|c|}
\hline Atividades & Aula 1 & Aula 2 & Aula 3 & Aula 4 & Aula 5 & Aula 6 & Aula 7 & Aula 8 \\
\hline Leitura de texto. & $\mathrm{X}$ & & $\mathrm{X}$ & $\mathrm{X}$ & $\mathrm{X}$ & $X$ & & \\
\hline Perguntas sobre 0 texto lido. & $\mathrm{X}$ & & & & $\mathrm{X}$ & & & \\
\hline $\begin{array}{l}\text { Escrita de frases pela professora, } \\
\text { no quadro, e leitura pelos alunos. }\end{array}$ & $x$ & & $x$ & $\mathrm{X}$ & $\mathrm{X}$ & $x$ & & \\
\hline $\begin{array}{c}\text { Oralização de frases sobre a } \\
\text { infância pelos alunos. }\end{array}$ & $\mathrm{x}$ & & & & & & & \\
\hline $\begin{array}{l}\text { Formação de frases a partir do alfabeto } \\
\text { móvel, em grupos de quatro pessoas. }\end{array}$ & & $\mathrm{x}$ & & & & & & \\
\hline Escrita de frases sobre juventude no caderno. & & & $X$ & & & & & \\
\hline Atividades de apropriação do SEA no quadro. & $X$ & & $\mathrm{X}$ & $x$ & $\mathrm{X}$ & $\mathrm{X}$ & $X$ & \\
\hline $\begin{array}{l}\text { Atividades de apropriação do SEA utilizando } \\
\text { frases de alunos no quadro: formação } \\
\text { de famílias silábicas. }\end{array}$ & & & $x$ & & & & & \\
\hline $\begin{array}{l}\text { Explicação pelos alunos de texto lido } \\
\text { pela professora. }\end{array}$ & & & & $\mathrm{X}$ & & & & \\
\hline Escrita de tarefa de classe no quadro. & & & & & & $X$ & & $\mathrm{X}$ \\
\hline Correção parcial de tarefa de classe. & & & & & & $\mathrm{X}$ & & \\
\hline
\end{tabular}


Pode-se perceber que, em cinco das oito aulas observadas, houve leitura de texto, sempre feita pela professora. $\mathrm{Na}$ primeira aula, ela releu o poema "Meus oito anos", de Casimiro de Abreu; na terceira, ela leu trechos de um poema de Fernando Pessoa ("Quadras ao gosto popular") e de Manuel Bandeira ("Trova"); na quinta aula, houve a leitura do texto "A história de Dulce" (retirado de um material que ela elaborou com alunos do Módulo 2, sobre histórias de vida); e, na sexta aula, também foi apresentado um texto biográfico intitulado "Folha amassada" (extraído da revista Pensamento, nov./dez. 2007). Algumas perguntas sobre o texto lido foram feitas.

Os textos lidos pela professora eram, na maioria, autobiográficos, uma vez que ela estava trabalhando a temática infância e juventude, em uma perspectiva de resgatar as histórias de vida dos alunos. Com tais atividades, observou-se que a docente buscava levar para a sala de aula textos significativos e, com base na sua leitura, realizava um trabalho de reflexão e socialização das próprias experiências de vida dos alunos. Após a leitura dos textos, atividades de escrita e leitura de frases sobre a vida dos alunos foram realizadas. Alguns alunos conseguiram produzir oralmente as frases, e a estagiária as copiava no quadro ou em uma cartolina. Vejamse alguns exemplos extraídos da primeira aula:

"Eu brincava de boneca"

"Eu jogava bola com meus amigos"

A escrita de frases, solicitada pela alfabetizadora aos alunos, era uma atividade realizada com frequência (esteve presente em seis das oito aulas observadas). No entanto, diante da dificuldade dos alunos com a escrita (eles estavam em processo de alfabetização), as frases terminavam sendo oralizadas pela maioria dos alunos, que não conseguiam escrevê-las, mesmo com o auxílio da professora ou da estagiária. O alfabeto móvel, utilizado por eles uma só vez, de igual modo, não ajudou, até porque, segundo a professora, eles não gostavam de manipulá-lo. Dessa forma, a docente, ou a estagiária, copiava as frases no quadro, as quais serviam de referência para a promoção de atividades que envolviam a leitura de palavras e sílabas.

A professora trabalhava as características do SEA a partir de alguma pergunta feita por um aluno ou por alguma frase escrita por eles, no caderno ou em uma folha de ofício, sem apresentar, explicitamente, objetivos didáticos específicos. Muitas dessas atividades envolviam 
questões ortográficas que pressupunham alunos que já estivessem em um nível alfabético. Alguns conteúdos trabalhados foram: formação de sílabas (primeira aula), separação de sílabas (quarta aula), explicação de família silábica e o uso do " $\mathrm{H}$ " (quinta aula), uso do "S" (sexta aula), número de sílabas de palavras e oralização, pelos alunos, de palavras terminadas em "ar", "er", "ir" e "or" (sétima aula). Conteúdos gramaticais também foram abordados, como na terceira aula, em que a professora trabalhou "verbos".

Não houve nenhuma produção textual, e foi pouco o envolvimento dos alunos em atividades de leitura e escrita, até porque poucos textos foram utilizados pela professora. Mesmo assim, os alunos sempre resistiam a todo tipo de proposta que envolvesse a escrita. A docente, em uma das aulas, comentou que os alunos sempre tiveram muita dificuldade em escrever e não sabiam explicar a razão disso.

\section{Práticas de alfabetização da professora Rubinalva}

A TAB. 2 apresenta as atividades relacionadas ao ensino-aprendizagem da leitura e escrita desenvolvidas pela professora Rubinalva, nos 10 dias de observação de suas aulas.

\section{TABELA 2: Atividades desenvolvidas nas aulas da professora Rubinalva}

$$
\text { Recife - } 2008
$$

\begin{tabular}{|c|c|c|c|c|c|c|c|c|c|c|}
\hline Atividades & Aula 1 & Aula 2 & Aula 3 & Aula 4 & Aula 5 & Aula 6 & Aula 7 & Aula 8 & Aula 9 & Aula 10 \\
\hline $\begin{array}{l}\text { Apresentação e discussão sobre o tema da } \\
\text { aula. }\end{array}$ & & $\mathrm{X}$ & & & & & & & & \\
\hline $\begin{array}{l}\text { Leitura de texto (histórias pequenas) escrito } \\
\text { no quadro pela professora. }\end{array}$ & $X$ & $\mathrm{X}$ & $X$ & $X$ & $X$ & & & & & \\
\hline Perguntas, no quadro, acerca do texto lido. & $X$ & & $\mathrm{X}$ & $\mathrm{X}$ & $\mathrm{X}$ & & & & & \\
\hline Leitura, em cartaz, de famílias silábicas. & $X$ & & $X$ & & & & & & & \\
\hline $\begin{array}{l}\text { Atividades de apropriação do SEA: } \\
\text { explicação e discussão, no quadro, sobre } \\
\text { a escrita de palavras e formação silábica. }\end{array}$ & & $\mathrm{X}$ & $X$ & & & $\mathrm{X}$ & & $\mathrm{X}$ & & \\
\hline Escrita e leitura, no quadro, de palavras. & & & $\mathrm{X}$ & & & & & & & \\
\hline $\begin{array}{l}\text { Elaboração de tarefas para alunos com } \\
\text { dificuldade de acompanhar a aula. }\end{array}$ & & & $X$ & $\mathrm{X}$ & $\mathrm{X}$ & $x$ & $\mathrm{X}$ & $\mathrm{X}$ & & \\
\hline Correção de tarefa de classe. & $X$ & & & & $\mathrm{X}$ & $\mathrm{X}$ & & & & \\
\hline $\begin{array}{l}\text { Atividade com livro didático (leitura } \\
\text { individual, silenciosa, de textos e atividade } \\
\text { de interpretação do texto lido). }\end{array}$ & & & & & & & $X$ & & $X$ & \\
\hline $\begin{array}{c}\text { Escrita, no quadro, de frases e posterior } \\
\text { leitura. }\end{array}$ & & & & & & & & $X$ & & \\
\hline Escrita de frase no caderno pelo aluno. & & & & & & & & $\mathrm{X}$ & & \\
\hline
\end{tabular}


Notou-se que a professora Rubinalva não possuía uma rotina sistematizada. Ela priorizou as atividades voltadas para a expressão oral e leitura de textos escritos por ela no quadro e daqueles presentes em livros.

Apesar de ela solicitar que os alunos lessem o texto no quadro, com ela, na realidade, ela fazia a leitura sozinha, pois a maioria dos alunos não sabia ler. Em geral, todos ouviam a leitura em silêncio. Não havia variação de gêneros, e, em muitos casos, ela fazia uso de textos infantis, tirados de cartilhas para crianças, ou elaborados por ela, como pode ser observado nos seguintes exemplos:

\section{Exemplo 1:}

\section{0 chapéu encantado}

Chica e Chaveco foram à chácara do vovô Michel. Lá, Chica perdeu o chinelo, a chave e o cachimbo do vovô.

Vovô ficou zangado e pôs Chica de castigo no quarto.

Chica achou o chapéu antigo e pôs na cabeça.

O colchão estava macio, e Chica dormiu de chapéu.

Ela acordou com a cabeça cheinha de ideias. Ela disse para o cachorrinho:

- Agora já sei onde pus o chinelo, a chave e o cachimbo do vovô. Ó, Chaveco! Eu acho que esse chapéu é encantado.

(PASSOS, Lucina Maria Marinho. Cartilha Alegria de Saber: alfabetização. Scipione, 1996.)

\section{Exemplo 2:}

\section{Dia do Professor}

No dia 15 de outubro é comemorado o dia do professor.

Professor é a pessoa que ajuda o estudante a vencer os obstáculos da vida.

Todo professor procura encaminhar seu aluno a uma aprendizagem, para que ele construa competências e tenha uma vida equilibrada no seu meio social.

O professor merece o respeito de toda a sociedade.

As atividades mais frequentes realizadas pela professora foram a leitura de textos e a elaboração de perguntas sobre eles. A alfabetizadora 
copiava as perguntas no quadro, mas somente dois ou três alunos respondiam, pois os demais diziam que não sabiam ler e escrever, e terminavam alguns deles oralizando as suas respostas.

Após o momento de interpretação do texto, a professora recorria ao quadro com padrões silábicos, que ficavam fixados na parede, para trabalhar algumas palavras do texto. As atividades de apropriação do SEA envolviam, principalmente, a leitura e escrita de palavras e dos padrões silábicos que as compunham. A separação silábica das palavras escritas pela professora no quadro também foi uma atividade realizada com certa regularidade. Para os alunos que estavam em fases iniciais do processo de apropriação da escrita alfabética, a professora propunha a realização de atividades que envolviam a escrita de palavras com apoio de figuras.

Como na sala da professora Marta, não foram observadas atividades que envolvessem a produção de textos. A professora disse que a dificuldade maior deles era com a escrita e acrescentou: "eles têm medo de errar e dos colegas rirem deles". Disse também que a atividade que propunha, para minimizar ou resolver essa situação, era o "uso de texto e cartaz", e que sentia a falta do livro didático, que não possuíam. Os alunos, dessa maneira, também não se envolveram, na escola, em práticas sociais de leitura e escrita, usando gêneros com os quais eles conviviam fora da escola.

\section{Análise das entrevistas com os alunos}

Nas entrevistas, os sujeitos foram questionados quanto à sua trajetória escolar e suas experiências escolares de alfabetização, relacionadas às práticas de leitura e, mais especificamente, de escrita. A pergunta inicial versou sobre o retorno dos entrevistados à escola. O primeiro grupo de resposta indicou que havia um desânimo por parte da maioria dos alunos (8) em retornar à escola, e muitos afirmaram que tiveram um "incentivo de alguém". Os motivos expostos para tal desânimo tinham relação com o fato de estarem trabalhando (3), ou já estarem cansados pela labuta da vida ou pelo serviço doméstico, ou por não se encontrarem bem de saúde. Apesar disso, sete alunos afirmaram que retornaram à escola, pois sentiam a "necessidade de aprender a ler e escrever", e somente uma aluna disse que a razão do seu retorno era para não ficar sozinha em casa e que gostava bastante do convívio com a turma. 
Ainda em relação aos motivos que os levaram a voltar a estudar, quatro alunos explicitaram que gostariam de "aprender a ler e a escrever". Quanto aos demais, outras justificativas foram dadas, também relacionadas, de certa forma, à aprendizagem da leitura e escrita: "para ter um futuro melhor" (3), pois viam na educação um caminho para vencerem na vida; para "não sofrer preconceito" (2), pois, no dia a dia, passavam por vários constrangimentos; e para "aprender alguma coisa" (3), no sentido de adquirir informações.

Quando perguntados se a escola podia atender às suas expectativas, a quase unanimidade dos alunos afirmou que a escola era, de fato, o espaço educacional que podia proporcionar "inteiramente" (15) o que eles desejavam. Segundo eles, as dificuldades que apresentavam na aprendizagem da leitura e escrita eram decorrentes de suas próprias atitudes. Somente um aluno achava que a escola atendia "parcialmente" a essas expectativas, pois faltavam coisas importantes, como o livro didático.

Em relação aos materiais que gostariam de ler, o grupo apontou "a Bíblia" como o livro-alvo de leitura almejada (8), por motivos distintos: por terem passado constrangimento na igreja, pelo fato de serem evangélicos ou católicos praticantes e por revelarem um profundo amor pelo texto bíblico. Os demais demonstraram desejos vários: "livro de matemática" (1), por gostar dessa matéria; "textos teatrais" (1), pelo fato de ter sido acompanhada, através de assistência psicológica, por alguém da família de Ariano Suassuna; "nomes próprios" (1), pois achava "triste não saber escrever"; "livros" (2), porque gostavam muito; "ler jornal" (1), a fim de acompanhar "especialmente as reportagens esportivas"; "poesia" (1), por gostar e ler "tudo o que vê na rua", para não passar por constrangimentos e ter que mentir, afirmando, por exemplo, que "estava sem óculos".

Em relação à escrita, muitos alunos (7) falaram que gostariam de escrever "cartas". Um aluno, ao destacar o desejo de escrever esse gênero textual, chorou, pois não conseguia escrever sozinho uma carta para pessoas queridas, que estavam distantes. Outras respostas se referiram ao desejo de saber escrever: "qualquer nome" (1), como os nomes de pessoas da família; "a própria história de vida" (2), pois tiveram uma vida muito sofrida; "um texto bíblico", para ser lido na liturgia da igreja; e o "próprio currículo", para quando fosse procurar emprego. 
Quando perguntados sobre o que tinham aprendido na escola, oito alunos disseram que aprenderam a "ler e a escrever um pouco", mas que sentiam ainda muita dificuldade. Outras respostas foram: "o nome próprio" (2), pois antes não conseguiam "escrever todo o nome"; "ler ônibus que usa", o que havia provocado um grande entusiasmo; "fazer conta" (3); e quatro alunos responderam que não aprenderam "nada" (4), o que gerava preocupação e a incerteza sobre se iriam continuar estudando. Um aluno falou que aprendeu a "conhecer e juntar um pouco as palavras", mas que continuava olhando-as sem conseguir ver sentido em nada.

A análise das entrevistas contribuiu para a percepção de que as expectativas que os alunos tinham, ao retornar à escola, para aprender a ler e escrever, não foram confirmadas, uma vez que a maioria deles não progrediu significativamente na aprendizagem da leitura e da escrita, e alguns culpavam a si mesmos por tal "fracasso". Somente um dos 16 entrevistados associou as dificuldades dos alunos no campo da leitura e escrita à prática da sua professora.

\section{Considerações finais}

Percebem-se semelhanças e diferenças nas práticas das professoras. Algumas semelhanças positivas podem ser destacadas no método das duas docentes, como o bom relacionamento com a turma e a assiduidade às aulas. Contudo, a análise das observações revelou que as alfabetizadoras possuíam uma abordagem de ensino da leitura e da escrita que distanciava os alunos das práticas sociais de leitura e escrita. A professora Marta proporcionava aos alunos momentos de leitura de textos significativos, como os poemas de autores consagrados (Casimiro de Abreu, Fernando Pessoa e Manuel Bandeira) e relatos biográficos produzidos por outros alunos da EJA. Já a professora Rubinalva realizava leitura de textos infantilizados e artificiais, característicos das cartilhas e livros didáticos tradicionais, o que limitava as experiências de letramento dos alunos. Em relação à alfabetização, ambas as professoras desenvolviam uma prática assistemática de alfabetização. A professora Marta priorizava a expressão oral e a construção e cópia de frases, para, a partir destas, desenvolver atividades sobre o SEA, mas de forma muito fragmentária. A professora 
Rubinalva utilizava os textos cartilhados para trabalhar famílias silábicas. Ambas ainda não aproveitavam o tempo pedagógico para promoverem atividades destinadas ao ensino sistemático do SEA.

As práticas das alfabetizadoras não levavam os alunos a uma reflexão sobre os princípios do SEA, nem ao envolvimento dos alunos em práticas sociais de leitura e escrita. Nessa relação entre prática pedagógica e aprendizado, é interessante perceber a fala da única aluna, que afirmou o seguinte: "Acho que a professora é [uma pessoa] boa, mas deixa correr frouxo. Não impõe limites e poderia ensinar melhor para aprendermos".

Vê-se que o tempo pedagógico deveria ter sido usado (talvez mais bem planejado) para levar os alunos a momentos de reflexão a respeito dos princípios básicos que compõem o SEA e à leitura e produção gradativa de textos. As professoras, ao trabalharem com alunos da EJA, não consideravam os conhecimentos que esses alunos, com certeza, já possuíam sobre a escrita alfabética, para, a partir daí, fazê-los avançar no processo de escrita. Por outro lado, realizavam práticas tradicionais de alfabetização, com ênfase no estudo de famílias silábicas. No caso da turma 1, constatou-se, inclusive, a presença de textos extraídos de cartilhas destinadas a crianças.

Faz-se necessária, assim, uma revisão em relação às práticas dos professores de EJA, desde a sua formação inicial e, também, durante a sua formação continuada, para que as necessidades do público da EJA, de uma alfabetização em uma perspectiva de letramento, sejam atendidas adequadamente. 


\section{NOTAS}

1 Esta pesquisa foi financiada pelo CNPq.

2 Barton e Hamilton (1998); Street (1984, 2009 e 2010)

3 Os nomes das professoras foram substituídos por nomes fictícios, no intuito de preservar a identidade das docentes.

\section{REFERÊNCIAS}

ALBUQUERQUE, Eliana Borges Correia de \& FERREIRA, Andréa Tereza Brito. 2008. A construção/fabricação de práticas de alfabetização em turmas de Educação de Jovens e Adultos (EJA). Educação. Santa Maria, v.33, n.3, p.425-440, set./dez., 2008.

ARAGÃO, Silvia de Sousa Azevedo. Relação entre a compreensão da escrita alfabética e o conhecimento das letras entre alfabetizandos adultos. Leitura. Teoria \& Prática, v.58, p.215, 2012.

BARDIN, L. Análise de conteúdo. Liboa: Edições 70, 1977.

BRASLAVSKY, B. O método: panacéia, negação ou pedagogia? Cadernos de pesquisa, São Paulo, n.66, p.41-48, 1988.

CERTEAU, M. de. A Invenção do Cotidiano. Petrópolis: Vozes, 1994.

CHARTIER, Anne-Marie. Trinta anos de pesquisas sobre história do ensino da leitura: que balanço? In: MORTATTI, Maria do Rosário Longo (Org.). Alfabetização no Brasil: uma história de sua história. São Paulo: Cultura Acadêmica; Marília: Oficina Universitária, 2011. p.49-68.

CRUZ, M. C. S. Tecendo a alfabetização no chão da escola seriada e ciclada: a fabricação das práticas de alfabetização e a aprendizagen da escrita e da leitura pelas crianças. 2012. 341f. Tese (Doutorado em Educação) - Universidade Federal de Pernambuco, Pernambuco, 2012.

FERREIRO, E. et al. Los adultos no-alfabetizados y sus conceptualizaciones del sistema de escritura. Cadernos Investigaciones Educativas, México, n.10, 1983.

FERREIRO, Emília; TEBEROSKY, Ana. A psicogênese da lingua escrita. Porto Alegre: Artes Médicas, 1984.

FREIRE, Paulo. A importância do ato de ler. São Paulo: Editora Cortez, 1985. Col. Polêmicas do nosso tempo.

GALVÃO, Ana Maria de Oliveira; DI PIERRO, Maria Clara. Preconceito contra o analfabeto. São Paulo: Cortez, 2007. Col. Preconceitos, v.2.

GALVÃO, Ana Maria; SOARES, Leôncio José Gomes. História da alfabetização de adultos no Brasil. In: ALBUQUERQUE, Eliana Borges; LEAL, Telma Ferraz (Org.). A alfabetização de jovens e adultos em uma perspectiva de letramento. Belo Horizonte: Autêntica, 2004. p.27-58.

GLÉRIA, Ana Carolina Faria Coutinho. Escola da vida: conhecimentos de adultos analfabetos sobre a escrita. 2010. 287f. Tese (Doutorado em Educação) - Universidade Federal de Pernambuco, Pernambuco, 2010. 
GOIGOUX, Roland. Méthodes et pratiques d'enseignenment de la lecture. Formation et Pratiques d'enseignement en questions: Revue des HEP de Suisse romande et du Tessin. n.1. Suisse: 2004, p.37-56.

LEAL, T. F. Estabelecendo metas e organizando o trabalho: o planejamento no cotidiano docente. In: Alfabetizar letrando na EJA. Belo Horizonte: Autêntica, 2010, p.93-112.

LÜDKE, Menga; ANDRÉ, Marli E. D. A. Pesquisa em educaşão: abordagens qualitativas. São Paulo: EPU, 1986.

MORAIS, Artur Gomes de; ALBUQUERQUE, Eliana Borges Correia de. Alfabetização e letramento: o que são? Como se relacionam? Como "alfabetizar letrando"? In: ALBUQUERQUE, Eliana Borges Correia de; LEAL, Telma Ferraz (Orgs.). A alfabetização de jovens e adultos em uma perspectiva de letramento. Belo Horizonte: Autêntica, 2004. p.5976.

MORAIS, Artur Gomes de. Sistema de escrita alfabética. São Paulo: Melhoramentos, 2012. MOURA, Dayse. C. Por trás das letras: as concepções e práticas de ensino do sistema de notação alfabética. 2001. 166f. Dissertação (Mestrado em Educação) - Centro de Educação, Universidade Federal de Pernambuco, Recife, 2001.

MORTATTI, Maria Rosário L. Os sentidos da alfabetização. São Paulo: Ed. UNESP; CONPED, 2000.

PERRENOUD, Philippe. A prática reflexiva no ofício do Professor: profissionalização e Razão Pedagógica. Porto Alegre: Artmed, 2002.

SOARES, Magda. Letramento: um tema em três gêneros. Belo Horizonte: Autêntica, 1998. SOARES, Magda. Letramento e alfabetização: as muitas facetas. Anais da $28^{a}$ Reunião Nacional da ANPEd, Caxambu, p.1-18, 2003.

Recebido: 28/02/2013 